\title{
Note
}

\section{Atmospheric waves as earthquake precursors seen in SODAR echogram}

\author{
M. Devi ${ }^{1}{ }^{*}$, S. Patgiri ${ }^{1}$ A. K. Barbara ${ }^{1}$ and A. Depueva ${ }^{2}$ \\ ${ }^{I}$ Department of Physics, Gauhati University, \\ Guwahati 781014, Assam, India \\ ${ }^{2}$ IZMIRAN, Troisk, Moscow, Russia \\ *Email: md555gu@gmail.com
}

\begin{abstract}
The Sodar echograms that give complete information on height, depth, temporal variations of convection and inversions in the atmosphere are utilized in the paper as sources of background information on atmospheric dynamics. Utilizing such atmospheric features from the SODAR operated at Gauhati University $\left(26^{\circ} \mathrm{N}, 92^{\circ} \mathrm{E}\right)$, the paper presents situations where development of waves in very near environment are observed prior to an earthquake. The analysis made in terms of components present in the wave and Froude number supports possible growth of such waves within the preparatory zone of the EQ.
\end{abstract}

Key words: Sodar; Convection; Earthquake waves; Froude number

\section{Introduction}

SODAR , the Sound Detection and Ranging is a remote sensing instrument that transmits a short acoustic pulse (typically $50 \mathrm{~ms}$ ) into the atmosphere, the signals are scattered back by temperature turbulences caused by the thermodynamic structure of the atmosphere [Little, 1969; McAllister et.al, 1969; Neff and Coulter 1986]. The backscatter signals provides fine scale atmospheric dynamic within the planetary boundary layer i.e. from the surface of the earth to about 1-2 kms, the key region in control of weather and climatic situation. The echograms presented by Sodar thus that give complete information on 
height, depth, temporal variations of convection and inversions in this region of atmosphere are the sources of inputs to retrieve structure parameter of temperature for understanding lower atmospheric dynamics [Soler and Hinojosa 1997]. Along with these observations, undulating structures especially atmospheric gravity waves are the subject of study by a Sodar because the waves could cause a redistribution of momentum and energy, trigger convection, and induce mixing [Hooke et al., 1972]. The resultant contribution of these waves is reflected as changes of the transport of chemical species there-by playing an important role in coupling processes of lower and upper atmosphere [Laštovička 2006 ;Yiğit and Medvedev 2015] Because of good resolution in heights, Sodars have been widely used for the last few decades in the study of atmospheric boundary layer and relevant information along with the turbulent status [Ostashev and Fairall 2002].

In this paper a brief description of overall atmospheric phenomena in general, based on features like inversion and mixing as reflected in echogram over Guwahati is presented Finally, a special feature generated prior to a strong earthquake (when probing station Guwahati lies very near to the earthquake epicenter) as seen in Sodar returns will be presented.

\section{Observations}

The analysis here is based mainly on data collected from Sodar operated at Gauhati University $\left(26^{\circ} \mathrm{N}\right.$, $92^{\circ} \mathrm{E}$ ). The basic component required for acoustic soundings include a transmitting system to illuminate the probing region and a sensitive receiver and a suitably designed antenna and signal processing units to receive the backscatter energy from the in-homogeneities present in the illuminated area. The GU transmits $1 \mathrm{KHz}$ signal with variable pulse length within 10-20 msec selected in a way to have height resolution of 6 to $12 \mathrm{~m}$ within the dynamical range of around $1 \mathrm{~km}$. The peak acoustic power of the transmitter is $80-100 \mathrm{~W}$.

In general two types of reflections are observed in a diurnal Sodar echogram. The reflections classed as shear echoes seen mainly as surface based structures, signify very weak or no vertical mixing, an example of which is presented in Figure.1. 


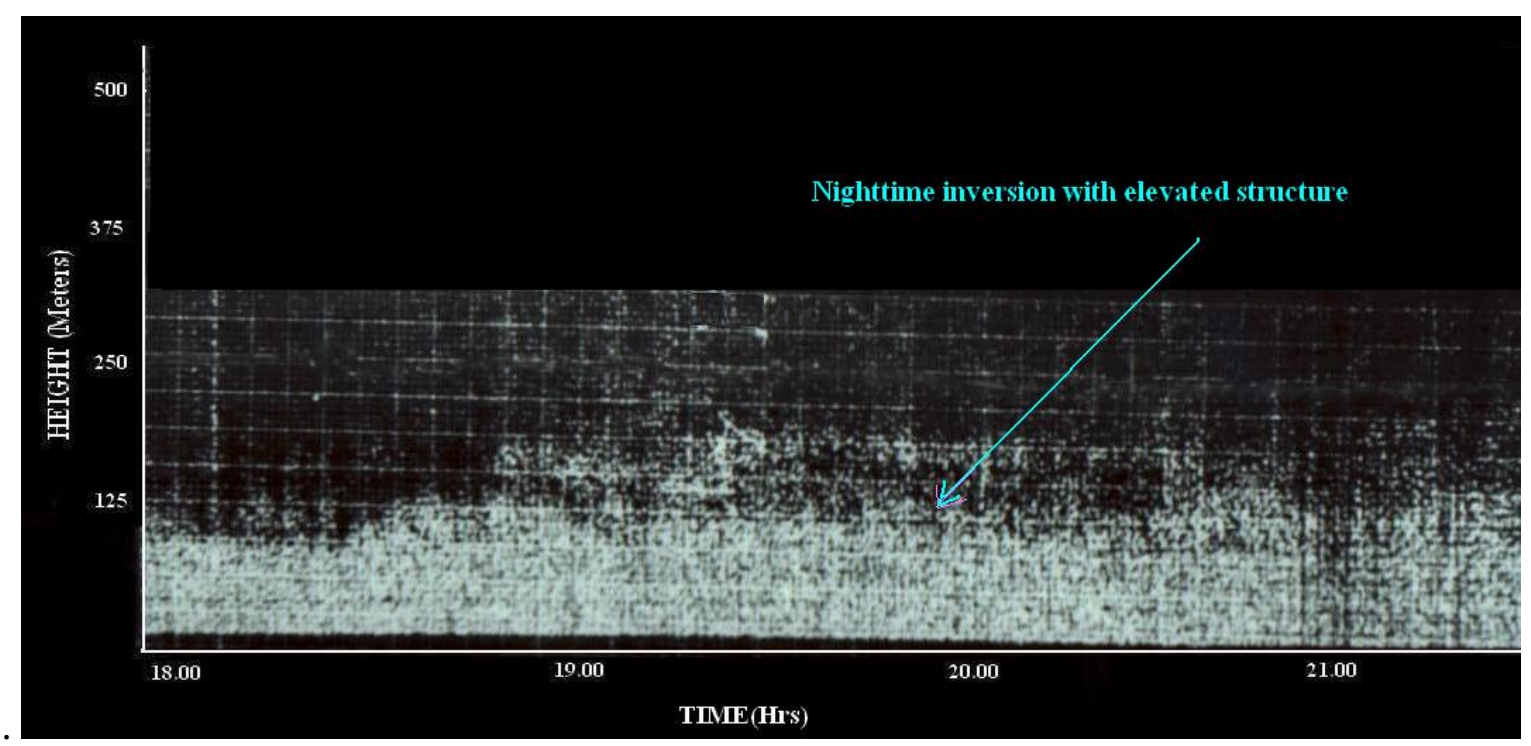

Figure 1 : Nocturnal Sodar echogram displaying inversion layer when vertical mixing is very week or totally absent.

Such echogram with surface based stable layer is seen during night hours when there is no source to heat the surface and is formed because of radiation cooling. The other type of reflections is from thermal echoes. Thermal echoes are governed by mixing of warm air (from warmer ground surface in most of the cases) and descending cool air. In Figure 2 we present a sample case of thermal echoes. Here blank region of the echogram reflects thermal plumes. These echoes are seen mainly during cloudless days and starts developing after sun warm the ground surface when convective wind builds up. The winds develop a mixed boundary layer and continued heating as day advances; as a result the height and rate of occurrence of convective plume increases, which become maximum by local noon.

Depending on temperature lapse rate, wind speed, cloud cover and frontal motions, there may be elevated layer, multiple layers and undulating reflection structures. A weak elevated layer and undulating feature is seen over the nocturnal inversion layer presented in Figure. 3. The echograms bearing such characteristics features of the atmosphere are however well documented in many literatures though each observation generally carry special significant from one location to another. However, besides these usual and normally observed atmospheric features, Sodar echogram has far 


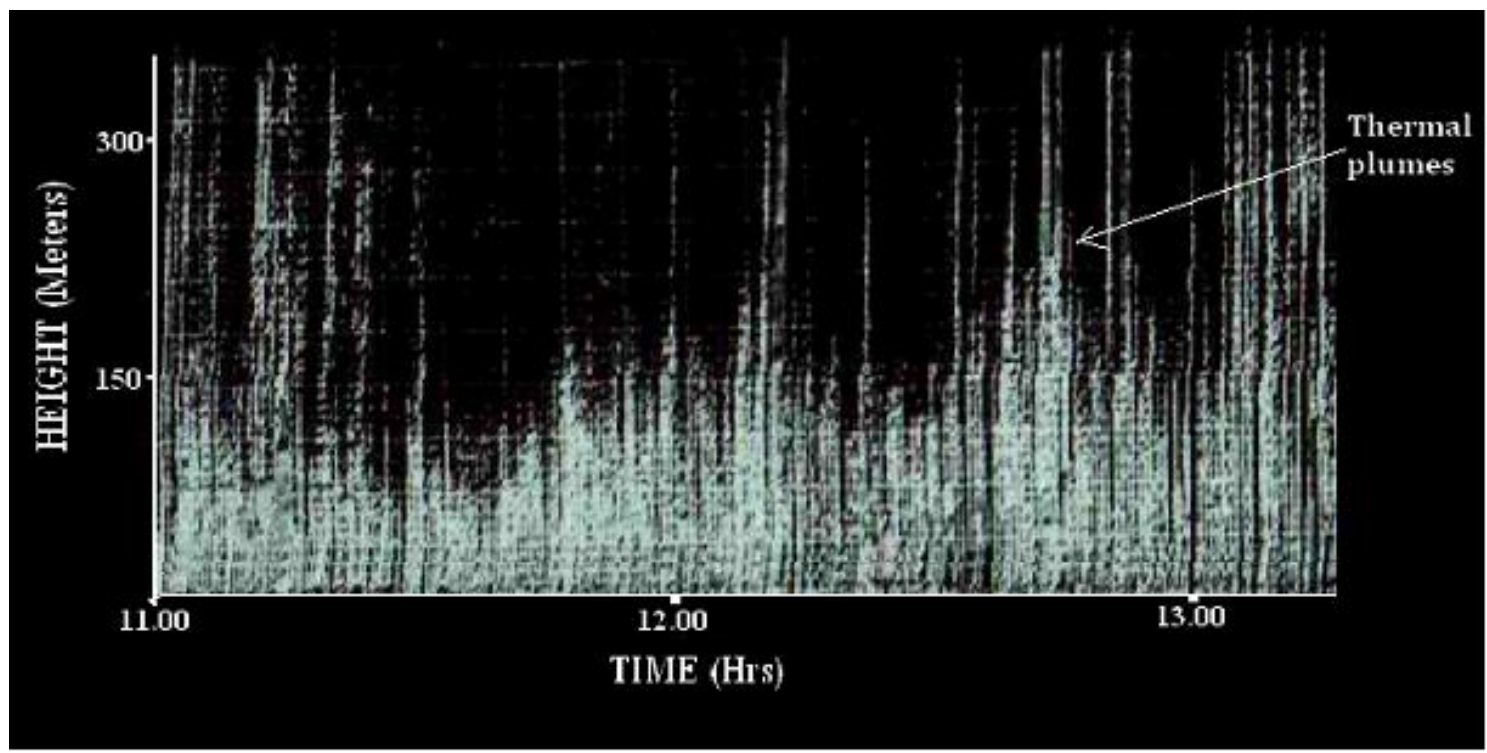

Figure 2 : Day time thermal plumes generated by convective situation

more potentialities in understanding atmospheric dynamics when special and unusual structures are present in the return echoes, one such event associated with an impending earthquake is presented in the following article.

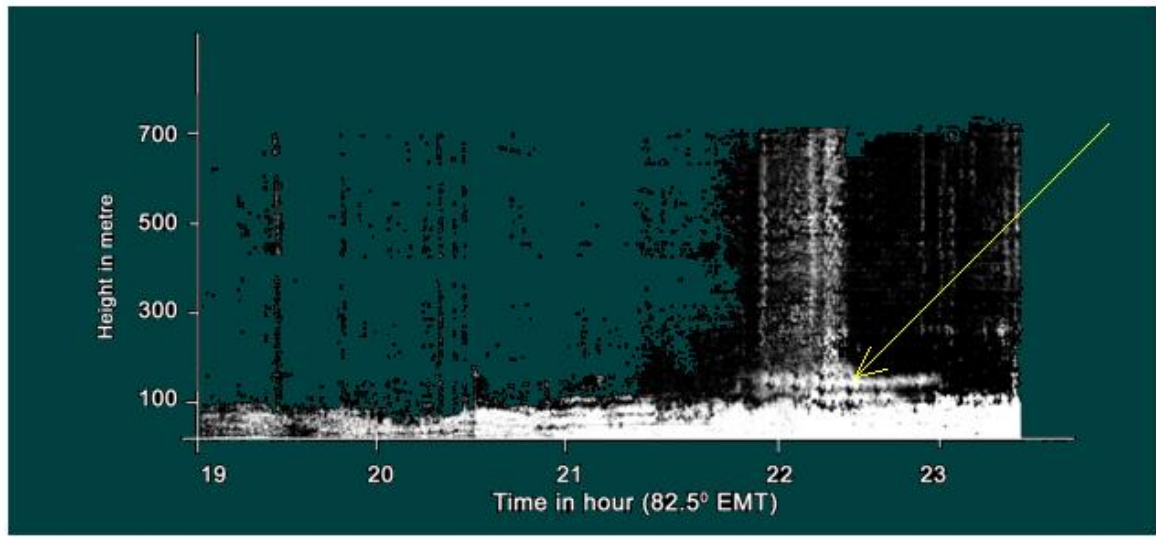

Thin elevated layer over nighttime inversions

Figure 3 : Weak elevated structure is seen over nocturnal inversions 


\subsection{Special Sodar structures associated with an earthquake}

Sodar echograms being reflectors of atmospheric dynamical situations, the extraction of information and source identification from the backscattered signals are complex process especially during atmospheric turbulent situations caused by natural hazards like earthquake .One such special case is displayed in Figure 4, when Sodar echogram during the night of November $18^{\text {th }}$ November 1996, [Devi et al., 2007 ; Devi et al .,2012] shows a few interesting features :

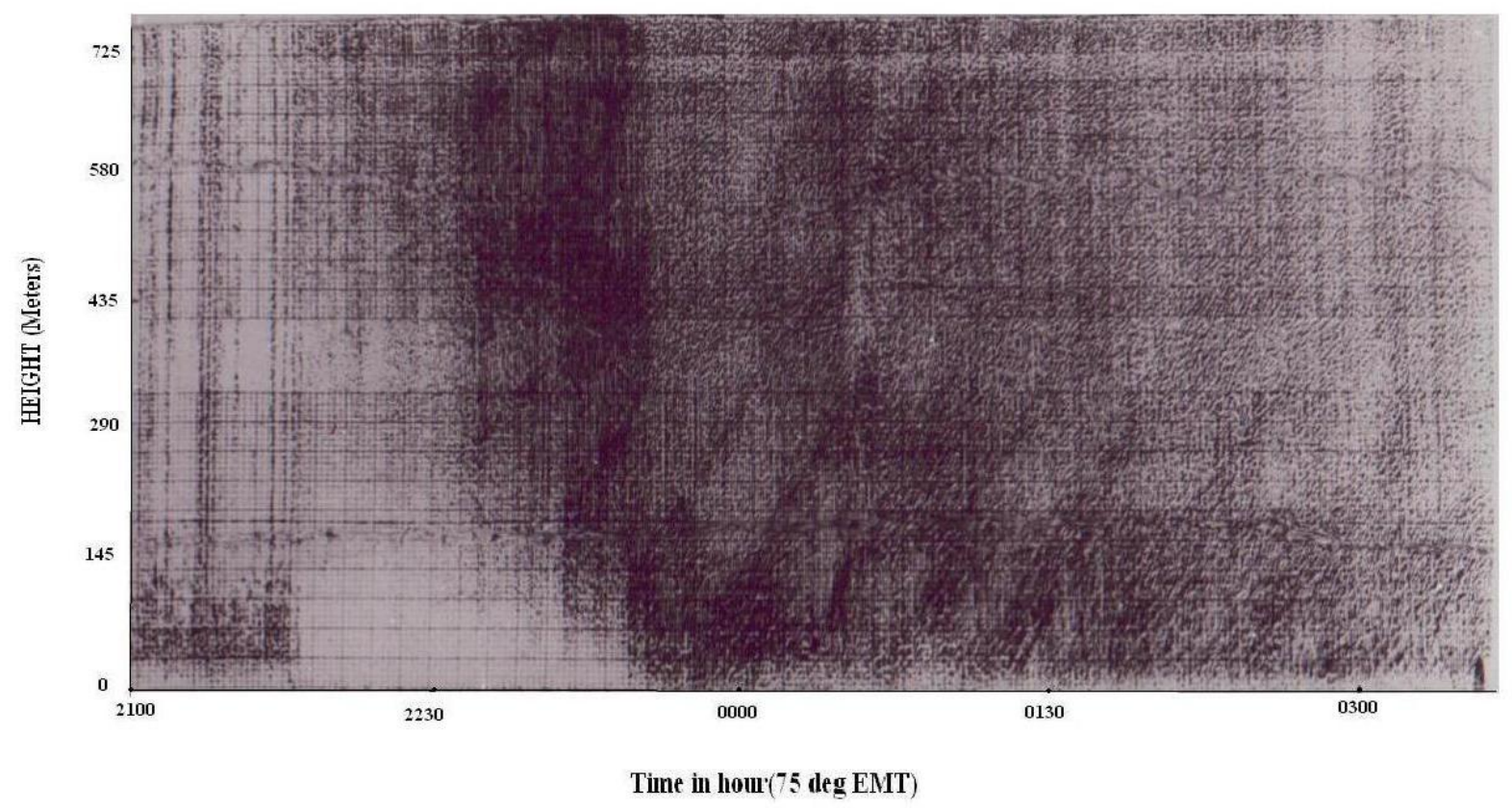

Figure 4: Compression and rarefaction of the wave in the atmosphere leading to slopping structures are seen prior to an earthquake of M.>5.5 occurred near to the observing site of the Sodar.[ Devi et al., 2007]

(i) Sudden break-down of surface boundary layer at around 2130 hours, unlike the normal situations when we see a steady inversion layer during night hours (as shown in Figure. 1) .

(ii) At the time of breakdown of the surface layer, the backscatter signals are observed only at high altitudes of around $450 \mathrm{~m}$; then as time advances, wave structures are seen 
progressively from lower altitudes till 2100 hrs when surface inversion stars building up again.

(iii) Development of slopping structures at around $2230 \mathrm{hrs}$, first seen at the highest probing altitude of the Sodar ( may be generated at still higher heights limited by the probing range of the system). As time advances, the structures are progressively seen at lower and lower heights till they reach the lowest probing range of the Sodar i.e., at the time when surface inversion builds up again.

(iv) Each structure maintains a clear individual identity with a positive slope in height-time frame and is embedded in a spiral like dense scattered zones.

Two potential sources for development of such waves are worst weather situation and hazards like earthquake. We put more emphasis on possibility of occurrence of an earthquake considering the season and background meteorological status. Significantly an earthquake of $M>5.5$ with epicentre around Guwahati , occurred a few hours after the Sodar detected the wave structures. To associate growth \& development of the waves with the EQ induced process, it is essential to extract its frequency and periodic components. The period of 15-20 minutes as seen in the Sodar echogram ( Figure 3) matches with gravity wave frequency at lower tropospheric height as observed by different techniques. Further, generation of gravity waves during earthquake preparatory processes is also reported by many The flowing discussions made in this context are supportive to this fact .

\section{Discussions}

One of the causes of development of turbulent stricture in the atmosphere is large and sudden enhancement in temperature caused by seismic induced effects. Such phenomena like increase in atmospheric /sea surface temperature, atmospheric humidity ,changes in water level, etc prior to an earthquake is unquestionable [Mogi, 1985; Hayakawa and Fujinawa 1994 ; Cervone et al., 2006 ; Devi et al ., 2010 ; Devi et al ., 2015]. Tronin [2002] has shown an increase in temperature of about $5^{0} \mathrm{C}$ along with slow undulations in temperature of 2 days in the area of strong ( $M=8.3$ ) Tonnaki earthquake of Dec $7^{\text {th }}, 1944$. Sudden increase in temperature by more than $4{ }^{\circ} \mathrm{C}$ prior to this earthquake was also noted in this earthquake time [Devi et al., 2000] when there should be a gradual decrease of its value as night 
progresses. This increase in temperature destroys the stability of earth's atmosphere at night which is otherwise very stable in absence of solar heating. The temperature anomaly further leads to convective situation as seen in the Sodar echogram of $18^{\text {th }}$ November. In such situation atmospheric variabilities undergo changes and may generate waves, one of the most known of the types is gravity wave. Such periodic oscillations seen prior to EQ could be coupled to the modification on natural oscillations of the atmosphere, by earthquake -induced irregularities or triggered by its preparatory processes . It is also known that that average atmospheric oscillations during stable condition ( known as buoyancy frequency) varying within 6 to 15 minutes which may get modified during abnormal situation when stability breaks down i.e., say in presence of strong changes in temperature lapse rate especially at nights. In such situations atmosphere may show turbulences in the form of waves triggered by the instability ( such as Kelvin Helmohtz type). The sloping or ramp -type structures as seen in the echogram indicate presence of slowly varying instability in the atmosphere. Such sloping structures are considered as manifestation of gravity waves, seen by Sodar at inversion heights and at ionospheric heights by MU radar [ Report of Kyoto university 2001]. The development of compression and rare-factions that are apparent in the case presented here is possibly due to the modulation of longitudinal or quasi-longitudinal waves like gravity waves and can be represented in wave- forms as shown in Figure 3. There are also reports that during the preparatory process micro earthquake appearances are accompanied by rarefaction and compression in wide frequency range [Solovivov 1997] an indication of possible development of EQ- time waves at the atmospheric height as reflected in the Sodar returns showing rarefaction and compressions.

Further, considering that the Sodar-waves appear first at higher heights, and then slowly creep down as time advances, the time period of the waves at a higher altitude will certainly be different from that observed at ground level, but to explain their appearance first at higher altitude , one might have to find out the secondary/induced effect of preparatory processes. One of the possibility of development of waves of the types at higher heights may be coupled to ejection of ions at altitudes greater than $1 \mathrm{~km}^{8}$. Along with this Clear Air Turbulence (CAT) factor may be added. In this process the cycle begins as the atmosphere is forced in to motion by differential heating. These motions while trying to find out equilibrium generate narrow layers where both wind and temperature variations are concentrated [Beer 1974]. Due to this effect. the gradient of these variabilities become sharper and at times it brakes and generate small scale irregularities. Added to such effects the turbulences result to mixing and in the 
process kinetic energy is converted to thermal energy. The explanation to our Sodar feature may be thus given as:

(1) Increase in temperature by the earthquake preparatory processes develops a differential temperature situation in the steady nocturnal atmosphere sharpening the density gradient or wind shear .

(2) Because of sharp gradient, system becomes unstable The accumulation of ion at the higher altitude accelerate the process of instability ( making the top layer heavier). If we assume that now forces of earth's gravity and the magnitude of stabilizing restoring force introduced by the density gradient are comparable to the compressibility force, then special structures or waves are generated known as gravity waves. They are quasi longitudinal waves

(3) Next we assume that wind shear becomes very strong when these waves breaks under the action of instability known as Kelvin Helmholtz instability and form patches like the ones we have seen in Sodar

We have already shown that the period of 15-20 minutes as seen in the Sodar echogram matches with gravity wave frequency at different atmospheric heights as observed by various techniques [ Fritis and Rastogi , 1985; Fritis et al, 1988, Zhang and Fan, 2007; Alexander et al., 2010]. Further, generation of gravity waves during earthquake preparatory processes is also reported by many [Horie et al 2007 ; Hayakawa et al ., 2009a; Hayakawa et al ., 2009b; Hayakawa et al .,2011]. In this aspect gravity wave period from a few minutes up to tens of minutes as reported by Pertsev and Shalimov 1996; Mareev et al., 2002 , may also be referred. Under these backgrounds the structures seen prior to the EQ are in the form of manifestations of gravity waves. It is also worth to calculate the value of Froude number (Fr) a dimensionless number defined as the ratio of a characteristic velocity to a gravitational wave velocity and to measures the significance of force of gravity as a restoring force in the development of waves, where $\mathrm{F}$ is defined by:

$$
\mathrm{F}=[\mathrm{U}\} / \sqrt{\mathrm{gL}}
$$

Here $\mathrm{U}$ gives wind speed at a height $1 \mathrm{~km}$ where density/temperature drops by half and for an acoustic wave to sustain $F$ value $>1$. .In our case we take these values from Radiosonde observation available just prior to the earthquake, almost 5 hours after the appearance of Sodar phenomena. From temperature and wind profile we get $\mathrm{L}=1.5 \mathrm{~km}$ (when temperature drops down by half) and prevailing wind velocity at 
that time at this height $U=120 \mathrm{~m} / \mathrm{sec}$. Using these values $\mathrm{F}$ value shows magnitude $>1$, indicating gravity wave could sustains in the background environment.

\section{Conclusion}

The EQ -induced gravity wave is seen in the Soadr echogram. The waves are generated at higher heights and slowly moves down to the surface layer height before dissipation. Temperature increase during the event specially during night time is an input to such instability.

The backscattered intensity of SODAR signal largely carries signature of varying temperature structure in the atmosphere limited by the probing range of 1-2 $\mathrm{km}$ and hence the source identification of waves at the altitudes beyond its probing range is not possible. With the newly established facility of Stratospheric Tropospheric (ST) radar at Gauhati University it is planed as future course of study to understand the growth \& development processes of such waves beyond tropopause and also the coupling mechanism between lower atmosphere to stratosphere. The ST facility will provide an unique scope to frame physical models of lithosphere-atmosphere-ionosphere coupling prior to earthquakes, as till now there is no common opinion concerning the formation mechanism of EQ generated waves at the lower atmosphere and their possible role at the ionospheric height or vice versa. 


\section{References}

Alexander MJ, Geller M, McLandress C, Polavarapu S, Preusse P, Sassi F, Sato K, Eckermann S, Ern M, Hertzog A, Kawatani Y, Pulido M, Shaw TA, Sigmond M, Vincent R, Watanabe S, Recent developments in gravity wave effects in climate models, and the global distribution of gravity wave momentum flux from observations and models, Quarterly Journal of the Royal Meteorological Society, 136, 1103-1124, 2010.

Beer Tom, Atmospheric waves edited by Tom Beer Wiley, John \& Sons, Incorporated, 1974.

Cervone G, Maekawa S, Singh RP, Hayakawa M, Kafatos M, Shevets A, Surface latent heat flux and nighttime LF anomalies prior to the Mw = 8.3 Tokachi-oki earthquake, Nat Hazards Earth Syst Sci, 6,109-114, 2006.

Devi M, Barbara AK, Barman MK, Heat exchange between adiabatically transported air parcels and the ABL, Indian J Phys 743(3), 345-347, 2000.

Devi, M., A. K. Barbara, Yu. Ya. Ruzhin, A. Depueva, Beyond the Horizon Propagation of VHF Signals: Atmospheric Features and Earthquake, Electronic Journal, Investigated in Russia, Vol. 129e, No. 39, 2007, 13311340, 2007.

Devi M., Barbara A.K., Kashyap P., Depueva A., Ruzhin Y.Y., Depuev V ., Earthquake time low latitude total electron content (TEC) variations and model based pattern: Identification of earthquake induced atmospheric dynamics. Adv Geosci 28:69-84, 2010.

Devi M., A. K. Barbara., Ya. Yu. Ruzhin, M. Hayakawa, Over-the-Horizon Anomalous VHF Propagation and Earthquake Precursors, Surv Geophys, , DOI 10.1007/s10712-012-9185-z, 2012.

Devi, Minakshi, Alaka Medhi , Ananda Kumar Barbara , Anan Depueva ,Yuri Ruzhin, Orographic role in Anomalous VHF propagation on the background of impending earthquakes ,Annals of Geophysics, ,Vol.58, 3, 2015.

Fritis D C and Rastogi P K , Convective and dynamical instabilities due to gravity wave motion in the lower and middle atmosphere : Theory and observations , Radio Sci., 20, 1247-1277, 1985.

Fritis D C , Tsuda T, Sato T, Fukao S, Kato S, Observational evidence of a saturated gravity wave spectrum in the troposphere and lower stratosphere, J. Atmos. Sc., 45, 1741-1759, 1988.

Hayakawa, M and Fujinawa Y (eds), Electromagnetic phenomena related to Earthquake Prediction ,TERRAPUB Tokyo, 677, 1994.

Hayakawa M., Seismogenic perturbation in the atmosphere. In: Hayakawa M (ed) Electromagnetic phenomena associated with earthquakes, Transworld Research Network, Trivandrum, pp 119-136, 2009a.

Hayakawa M.,Lower ionospheric perturbations associated with earthquakes, as detected by subionospheric VLF/LF radio signals. In: Hayakawa $\mathrm{M}$ (ed) Electromagnetic phenomena associated with earthquakes. Transworld Research Network, Trivandrum, pp 137-185,2009b.

Hayakawa M, Kasahara Y, Nakamura T, Hobara Y, Rozhnoi A, Solovieva M, Molchanov O A, Korepanov V, Atmospheric gravity waves as a possible candidate for seismo-ionospheric perturbations, J Atmos Elect., 31:129$140,2011$. 
Hooke WH, Young JM, Beran DW, Atmospheric waves observed in the planetary boundary layer using an acoustic sounder and a microbarograph array, Boundary-Layer Meteorology, 2: 371-380, 1972.

Horie T, Yamauchi T, Yoshida M, Hayakawa M , The wave like structures of ionospheric perturbation associated with Sumatra earthquake of 26 December 2004, as revealed from VLF observation in Japan of NWC signals, $J$ Atmos Solar-Terr Phys, 69:1021-1028, 2007.

Laštovička J ,Forcing of the ionosphere by waves from below, J Atmos Sol Terr Phys, 68:479-497, 2006.

Little C G , Acoustic methods for remote probing of lower atmosphere , proceedings of the IEEE, 57, 571-578, 1969.

Mareev E.A, Iudin D.I., Molchanov O.A., Mosaic source of internal gravity waves associated with seismic activity, In: M. Hayakawa and D. Molchanov (eds.), Seismo-Electromagnetics (Lithosphere-Atmosphere-Ionosphere Coupling), Tokyo: Terra Scientific Publishing Company, 335-342, 2002.

McAllister L. G., Pollard J. R. , Mahoney A. R., Shaw P. J .R. , Acoustic sounding : approach to study of atmospheric structures, IEEE Proc , 59, 579-587, 1969.

Mogi K., Earthquake Perdition, Academic Press,1985.

Neff W. D. and Coulter R. L., Acoustic Remote Sensing in probing in the atmospheric Boundary layer, American Meteorol. Society, Boston, Massachuttes, USA, 201,1986.

Ostashev, V.E.; Fairall, C., Turbulent contributions to the echo-signal recorded by a monostatic sodar, Geoscience and Remote Sensing Symposium , 2002. IGARSS apos;02, IEEE International, 865 - 867 vol.2, 2002.

Pertsev N.N., Shalimov S.L., Generation of atmospheric gravitational waves in a seismo-active region and its influence on the ionosphere, Geomagn. Aeron.,, Vol. 36, No. 2, 111-118, 1996.

Report of Kyoto University Radio Science Centre for Space and Atmosphere, Feb. pp19,2001.

Soler M R and Hinojosa J A , Study of thermal and dynamical atmospheric boundary layer strictures using acoustic sounding, Int J remote sensing , 18 (5) , 1149-1165, 1997.

Solovivov, S L., Achievements and Problems of sea seismology, Nauka , Moscow, 163-166, 1997.

Tronin Andrew, Atmosphere-lithosphere coupling: Thermal anomalies on the earths surface in seismic processes, Seismo Electromagnetics -Atmosphere -Ionosphere Coupling: Eds. M. Hayakawa and O.A. Molchanov., 173-176, 2002.

Yiğit E, Medvedev A.S., Internal wave coupling processes in earth's atmosphere, Adv Space Res, 55(5):983-1003, http://www.sciencedirect. com/science/artic, 2015.

Zhang Shao Dong and Yi Fan, Latitudinal and seasonal variations of inertial gravity wave activity in the lower atmosphere over central China, Journal of Geophysical research, VOL. 112, D05109, doi:10.1029/2006JD007487, 2007. 